\title{
Tiempo de amar
}

\section{TE ALABARE, SEÑOR}

Te alabaré, Señor, con mi plegaria que nunca he preparado ni repetido y que sólo será bella porque tú la escuchas.

Porque mi corazón se cansa de leerte por los libros que no tienen rostro y siente asco del miedo que existe a pronunciar tu nombre.

Mi plegaria es audaz y sincera, pero tosca; sencilla, pero llena de todo: de mí mismo y del mundo que vive conmigo y lo que pasa en él.

No podré decirla de una vez, ni a un tiempo fijo, porque la vida se está haciendo en cada hora y tú pasas por ella y en ella aprendo yo las palabras que quiero decirte.

Te recordaré cuando la marea en torno mío me penetre con un clamor humano por todos mis sentidos

y me haga suspirar o maldecir, protestar con dureza o maravillarme y concentrarme en el amor del silencio.

Porque entonces tú me llamas y me traes lentamente hacia donde tú dejas de ser lejano, el Dios de los que no te conocen,

y empiezas a ser el amigo que envuelve en la plenitud de la sabiduría, capaz de descubrirme la única verdad que necesitamos.

\section{LA VIDA ES BUENA}

Acuérdate de nuestro mundo y vuélvelo a mirar, como al principio, con ojos de complacencia ensimismada,

porque la luz era buena y las cosas que crecian por la superficie y los animales amansados que salian de su cueva al clarear de la mañana. 
$Y$ bueno era el hombre, sin diferencias de color, ni prejuicios, ni miedos; sólo con el asombro que le rodeaba por todas partes.

$Y$ estaba todo en condiciones para vivir, trabajar, amarse de verdad $y$ hacer en cada día nuestra historia.

Pero la vida se ha trabado en una red que traza como el acero $y$ entorpece la libertad hermosa que nos diste.

$Y$ aunque todo sigue en su sitio y las maravillas se van multiplicando en juegos infinitos, nos duele el mal y los derrumbamientos.

Nos duele la mentira que propagamos nosotros mismos y asi tu don se ha convertido en un tesoro que con su brillo hiere nues. tros ojos enfermos.

La vida es buena, pero con frecuencia no sabemos continuar hacién. dola, ni amarla sabiamente y en el corazón de carne que nos diste hay un clamor que se escapa hacia no sabemos dónde: tan pronto hacia lo que alegra momentáneamente para luego de. jarnos cansados $e$ insatisfechos, perdidos en nuestros propios laberintos,

como sube hacia ti con palabras temblorosas, pero expresivas, calientes con el rescoldo de aquel fuego aue encendiste dentro de nosotros.

\section{EL NUEVO AMOR}

En el principio era el amor y seguirá siendo para siempre mientras nosotros amemos de verdad la fuerza creadora, la ilusión que alegra profundamente, la pura maravilla de los hombres.

Por eso te pido que nos conserves el amor de los que se aman por primera vez, ya que han descubierto las raices de la vida.

Porque ellos, los amantes, ocupan el sitio más seguro y a la vez más incierto de la existencia; el más habitado y el más solitario.

En sus ojos se ha abierto el horizonte más amplio, donde aparece la única estrella oue puede creerse que hay en el cielo,

y con sus tanteos de ciego y sus balbuceos de niño, han hallado la verdad más primitiva y gozosa, capaz de brillar sobre todas las sombras imaginables. 
Déjales en su misterio dulce compartido cada día, con sus recuerdos intactos y sus citas imborrables.

Que nadie les estorbe en su aventura porque tú estás entre ellos, despejando los caminos por donde se hace nuevo otra vez este viejo mundo.

Después de ellos ya casi no queda más que un vacío inmenso que nadie sabe cómo puede llenarse y mientras haya una llama así en sus corazones tendremos motivos para esperar conocerte a ti. y llegar al encuentro definitivo.

Pero quiero para ellos el sentido de lo que no perece en las mismas palabras hermosas o en los gestos de ternura,

porque todo amor tiene que transformarse en fruto de vida para más allá del tiempo y permitir que la luz no se apague donde se encendió una hoguera

y alguien, desde algún sitio, nos pueda llamar por nuestros nombres sin mancha cuando todo termine.

\section{UN GRITO QUE SE ESCAPA}

Yo te pregunto, Señor, si oyes también el grito que se escapa de nuestra vida inmersa en la tragedia que intentamos disimular sin conseguirlo:

es el dolor, el odio y el cansancio, que nos clavan un dardo en el corazón y nos derriban;

es la injusticia de los que son más fuertes, el desamparo de los que son más débiles; la pobreza que hinca su diente cruel y muerde a tantos hombres;

es la mentira y el pecado, que no podemos paliar y que como un gusano terco va pudriendo nuestras obras.

Pondré mi corazón en el silencio y que él te pregunte y te invoque sin vergïenza.

Pero tampoco me importa clamar en voz alta, cuando compruebo la miseria en que nos hundimos desde hace tanto tiempo.

Tú eres mi Dios al fin y yo el pobre hombre que, con otros muchos, aguardan sentados como al umbral de tu morada la luz de una respuesta,

para encontrar la paz perdida y descansar con el reposo verdadero.

Porque tú eres la gravedad a la aue se inclina sin remedio el hombre 
que creaste con tus manos y la única alegría que penetra como el agua de los manantiales por la tierra áspera y en. durecida y la plenitud que corona las cosechas.

\section{LO QUE QUEDA DE ESPERANZA}

Sálvanos lo que queda de esperanza humana, dolorida y difícil, enigmática y pura en esta juventud que viene desde lejos.

Sabemos que la vida es una rueda de molino que tritura entre sus dientes implacables los huesos de los viejos;

pero que es inútil $\mathrm{e}$ innoble negarse a que aquellos estén aquí, a que rehagan la existencia y la condicionen, nos hablen y nos pidan.

Ellos son el agua clara en sus comienzos, velocísima, que baja brotando por gargantas y pedregales con su cauce hinchado de voces, de pasión, de fuerza

y cubrirán de humedad prometedora nuestros valles, donde se siente cada año, desde siglos, la alegría de las estaciones.

Es posible que arrastre muchas cosas a su paso, que sobrecoja de temor, que haga bajar la frente de vergüenza o de remordimiento.

Pero será la vida, el don que nos haces para este tiempo, la juventud que merecimos.

Sálvala de sí misma y de nosotros, las generaciones que la miran cada una con un latido diferente y le alargan la mano con un gesto distinto,

porque son tus hijos, los que traducen el sentido de lo que falta y nos traen la memoria de lo que olvidamos con tu nombre o sin él.

\section{ARMADORES DE MUERTES}

Apártalos como mejor puedas con tal de que no volvamos a sentir el contacto de reptil en nuestra piel castigada,

a los que en sus bufetes confortables hacen cálculos de muerte y con frialdad discuten conveniencias en términos politicos que nadie comprende de verdad 
$y$ en la balaniza que ellos manejan ponen metales agudos por millones $y$ hombres; poder de destrucción y hombres: muerte a precio de mercado negro y hombres.

$Y$ esperan el resultado tan tranquilos haciendo un sucio juego con los ansiosos infelices y los torpes, los ambiciosos de tierra $y$ de gloria, los débiles que malestrenan su coraje y los demasiado listos.

Tú que eres el creador incansable de la vida, que eres paz, lealtad $y$ razón de amor, aplástales a los unos y abre los ojos del corazón a los otros.

Pon tu fuerza silenciosa sobre los que presumen de fuertes y hacen sus planes a la luz del día, a primera plana del periódico $y$ tratan de justificarse.

Estos no se acordarán de los que quedan atrapados en sus redes, ni tienen tiempo para escuchar clamores de protesta, ni soportan la relación de sus muertos.

Pero Tú eres justo y se los pondrás en los entresijos: y se los harás pesadilla de sus sueños y angustia de su soledad.

Que tu mano les haga el signo del amor entre los hombres que nunca quisieron atender.

\section{TE ESTAMOS ESPERANDO}

Nos vamos por la calle donde se oye el rumor de lo que vive y nos hacemos presentes con gozo por que aquí está la verdad de lo más nuestro,

esperando que llegue como una lluvia fresca sobre el asfalto y limpie el polvo que se nos queda sobre nuestras cosas, tu redención.

A nuestras calles pobladas, a nuestras casas donde hay una mesa en la que se apaga el hambre de la jornada y un sitio para el amor.

Te estamos esperando como a una señal de paz para nuestras frentes, como a un viento de justicia y comprensión para todos,

mientras suena el ruido de las fábricas y el rumor de los peatones se hace plegaria con aliento de trabajo interminable.

Aquí estamos todos los días, sin fecha ni lugar concreto para encontrarte, pero esperando, siempre esperando: 
los mayores de entre nosotros que han vivido la guerra y han hecho un hogar multiplicado, los jóvenes que hierven con el fuego de todos los posibles y los niños totalmente puros.

$\mathrm{Ya}$ es lo único importante que hacemos para el día verdadero, aunque no sepamos expresarlo exactamente y con frecuencia seamos la imagen del abandono y la incredulidad.

Te esperamos a ti, Señor, te esperamos de todas las maneras porque en nosotros no puede borrarse tu memoria ni la huella profunda de tus dedos.

\section{TODO UN HOMBRE}

Necesitamos de ése hombre, del hombre justo que ama la verdad donde se encuentre $y$ no teme el compromiso en que se mete, ni se duele del amor que testimonia a los otros.

El hombre honrado pese a todo y contra todos, que no se doblega ante los idolos creados por la propaganda y el brillo de un poco de fama.

A ése que se hace fuerte con paciencia en el silencio activo, cuando todos dan voces y critican sin saber porqué;

a ése que no se deja llevar de la soberbia que atenaza como una soga al cuello, ni de ambiciones torturantes $y$ dificiles;

a ese hombre que no es de piedra sino de carne, pero que se apoya en la lenta reflexión sobre la vida.

Quizás esté muy cerca de nosotros y no le hemos visto. $O$ quiso hablar y se marchó porque no le escuchamos. Acaso nos hemos burlado de él por estúpido o le insultamos como a ig. norante.

El sabe que es muy pequeño y que su fuerza se pierde como una hoja en el fragor inmenso de la mar sobre la que flota con nos. otros,

pero tiene una fe que crece en su corazón como un retoño bien defendido, inserto por el tronco donde palpita la savia que le da vida.

Se ha hecho fuerte en su destino, que para él es como una llamada de amor que desde lejos le va empujando a terminar su obra momento a momento, con fidelidad.

Necesitamos a este hombre con nosotros para hablar con él, para can- 
tar con él, para soñar con él mientras caminamos. Porque lo habiamos olvidado y no sabiamos cómo empezar de nuevo.

\section{EL MUNDO RUEDA}

Me hace pensar el mundo que rueda a través del sol y de la niebla, de los días de canciones y optimismos, y de los días de desgracia, de los caminos con porvenir y de los callejones sin salida,

porque rodando con él vamos nosotros, carne de su carne, tierra de su tierra, pulso caliente y voz que resuena por sus túneles fecundados.

Aspero mundo de las desigualdades y las sorpresas dolorosas, de la escasez y la mala suerte, de la locura alegre y los placeres.

Mundo nuestro de la bondad inefable y la malicia incomprensible, de la risa y el llanto, del poder y la imposibilidad,

capaz de compadecerse e indignarse y de olvidarse de todo cuando brilla el oro del poder y la gloria.

E1 tiempo va pasando y cada vez parece más lejano e irreconocible ese Dios del que hablan los piadosos.

$\mathrm{Y}$ aunque es verdad que tenemos infinidad de preguntas que hacer, de inquietudes que confiar, de preocupaciones que resolver, nos lo aguantamos y damos vueltas sin parar.

Hasta cuándo? Quisiéramos detenernos acaso para juzgar, pero nos sentimos juzgados. Ya no tenemos tiempo, aunque lo perdamos. Nada tiene remedio, decimos, aunque nada hemos intentado por que lo tenga.

Sólo Dios signe nuestros prsas. Y en silencio va dejando señales, como perdidas en la noche, para nosotros que pasamos de prisa, de un lado para otro.

\section{ı. ESTOS QUE CRECEN}

Miralos con amor a estos que crecen con la pasión terrestre de los árboles y los ríos, nuestros jóvenes hermosos y alegres con la frescura de lo nuevo. 
Ellos dicen que vienen de las cuevas, del desierto, del país de la muerte $y$ del olvido y que nacieron por primera vez en su propio amor.

$Y$ sin embargo son los rostros mismos de los que crecian lentamente en los bancos de la clase y en los parques jugando muy cerca de nosotros.

Son los mismos, pero acaso sean también ya otros. Tienen la fuerza y el miedo, la dureza y la ternura, la sencillez y el misterio mezclados en sus venas.

Escúchanos: cuida su valentía y machaca su mentira. Defiéndelos de las trampas y cárgalos con el trabajo.

Sácales del olvido y a los demás enséñalos a agradecer su sonrisa y su canción, su incansable imaginación que busca la fertilidad de la vida por doquier.

Guárdalos no para la guerra y la maldad, sino para el bien que en la armonia construye la casa y pule el metal, labra la tierra y perfecciona el poema.

Si se sienten peregrinos enséñales que la santidad humana está también llena de tu gracia que es plenitud de amor y orientación hacia la verdad.

$Y$ serán la sangre nueva que nos hace falta, la claridad que nos mortifica en nuestra costumbre de oscuridad, el barro para tu tierra nueva y la estrella para tu cielo nuevo.

\section{I1. ESOS COMBATIENTES}

Dales la paz a los que por inconsciencia o por obligación o por la inercia de las situaciones que empujan, alargaron las manos a las armas y las empuñaron para combatir.

$\mathrm{Y}$ por ello tuvieron que entregar a sus amigos de ayer o vieron cercados de enemigos el umbral de sus casas.

Y día a día pagaron en su propia carne al precio del tormento, del cansacio $\sin$ tregua, de la triste soledad, la victoria del odio.

Porque lo han dado todo y son los más vacíos del mundo: dieron el oro de su paz y el amor que tenían para construir la vida.

Y ahora andan errantes por caminos de fuego y por trincheras que nunca se retiran de verdad, endurecidos y desafiantes como alimañas. 
Son los más pobres aunque les llamen héroes; los más muertos, aunque todavía respiren - tú lo sabes-y sus aspiraciones vagan por un cielo sin retorno.

Lejos está la ciudad y la casa, la dulce caricia y el pan de su tierra, la fuente de agua y la estrella con su luz de esperanza sobre el tejado.

La guerra será tan larga como la vida. Ellos lo sospechan y tú estás en el peligro como una sombra de justicia para el final.

Nosotros irónicamente les cubrimos de una gloria que es como una niebla para sus ojos que querrían ver más allá de la muerte.

\section{YO SOY UN MENDIGO}

Yo soy un hombre cualquiera y un mendigo que pasa haciendo su jornada por delante de tu puerta.

Llevo un andar vacilante por el mundo donde nunca encontraré la morada que me dure ni el apoyo fuerte donde poder descansar sin miedo.

No llevo la inquietud del que escudriña en sus máquinas de cálculos exactos,

ni soy el sabio, ni el politico ni el poderoso que convierte el lenguaje de las cosas a su capricho.

Sólo un hombre a quien todo lo humano le importa, pero que ha aprendido la verdad de su propia indigencia, y en cuya vida tú eres la suprema inquietud.

Me he puesto a considerar las necesidades que entusiasman y aprisionan al mismo frente a la dura libertad y escojo ésta para siempre.

Pero no estoy lejos de nada, sino cerca, metido en el corazón mismo de las cosas, aunque quiero respirar con la fuerza de mi propia sangre.

Porque hay muchos que viven cerca de todo y sin embargo lo más hermoso de la vida se les escapa de entre las manos y se ignoran a si mismos.

Prefiero ser el mendigo de tu sabiduria, un hombre cualquiera que aprende el abc de cada dia lentamente,

capaz de sorprenderse ante el misterio, de desear la luz, de amar al hombre, de recordarte a ti, de aventurarse tras una llamada. 
$Y$ no olvido que todo puede ser verdad en torno mio y que mi virtud posible es descubrirla a tiempo y aceptarla.

\section{TODOS SOMOS POBRES}

Dale, Señor, a este mundo donde todos somos pobres de algo, tu calor de Padre, porque tú eres bueno y puedes darnos a su tiempo lo que necesitamos.

Calma los odios y las desconfianzas para que podamos pensar en lo que ocurre y por qué somos lo que parecemos.

Tú sabes que nos duele y nos molesta, nos oprime y nos avergüenza la pobreza: no tener lo que otros tienen, no llegar adonde otros llegan.

Pero no dejes que la austeridad sabia del poseer y el despojarse deje de ser un camino en claridad para nuestro peregrinaje.

$\mathrm{Ni}$ permitas tampoco que el mal y la hipocresía nos engañe para dejar que nuestro intento de un mundo mejor para todos se desmorone.

No preferiremos la riqueza a la pobreza, ni la abundancia a la escasez, sino la manera de estar en el mundo libertados.

Por el trabajo que podemos hacer y la constancia, por la sobriedad y la justicia, por la condescendencia y el combate leal, llegaremos a dominar la tierra,

pero la perderemos a medida que algo de ella nos esclavice, sobre todo la miseria sin dignidad o la abundancia soberbia.

Por eso, enséñanos a salir hacia todos los caminos posibles donde se hace algo con la serenidad del hombre que sabe que en su mano tú has puesto un poco para cada día.

\section{I4. VOLVEREMOS A TI}

Volveremos a ti con el alma cansada y anhelante, rumiando la experiencia de la vida.

Qué cosa pudo deslumbrarnos o qué palabras pudieron minar aquella fe que teníamos en ti?

Qué circunstancias complicadas nos fueron enredando y obligando 
hasta llevarnos lejos de nosotros mismos?

Por fortuna pudimos detenernos a pensar. Era la suerte mejor que nos cabía porque, aunque tarde, todo podría estar de nuevo en nuestras manos.

Cómo nos duele ver lo que perdimos en el tiempo, construyéndonos un mundo sin base de esperanza!

$Y$ cómo duele por dentro esta andadura fatigante entre las cosas, pe. regrinos sin remedio hacia un final que se acerca preguntando!

Volveremos a ti con la ofrenda del amor y los anhelos, lo único que queda de tanto como se ambiciona, se apuesta y se conquis. ta.

En el alma la verdad de lo que somos, al descubierto al fin, sin excusas ni fáciles lamentos, con gesto decidido de presencia.

En cualquier dia y cualquier hora podremos encontrarte. Porque lo creo, siento crecer en mi la esperanza que redime.

Tú estás en todas partes y lo entiendo. Ofreciéndome el agua de la vida, la luz que no hace daño y la alegría verdadera,

el amor definitivo, la paz buena y deseada, la palabra eterna que nos salva.

\section{HERMOSO ES EL AMOR}

Alegraos viendo el amor cómo echa sus raíces en los corazones de los hombres y deja su savia dulce palpitando en todas partes.

Porque así crece la vida con el signo que da razón de ser a lo que somos.

Hermoso es el amor, por sus palabras, por sus gestos, por su esperan$\mathrm{za}$, por su inquietud, por su don que va de un hombre a otro como un fuego.

Dios lo hizo así : alegraos cuando llegue a vuestra casa, a vuestras vidas, reuniendo los azares imposibles, los asombrós y las incertidumbres.

Salid a la calle y admiraos, porque en los parques el hombre y la mujer intentan saberse amados y là caricia viene a ellos como el aleteo de un pájaro.

Tras de los ojos que cierran su secreto, la ternura se hace sabor de la existencia. 
Es el amor humano que se instala en el mundo perenne y batallante, tenaz y sencillo, tremendamente confiado, siempre antiguo y siempre nuevo.

Nadie nos lo enseñó porque lo aprendimos un día de claridad y de gozo, cuando la verdad era nuestra y la pura libertad se adhería a nuestra piel reciente como un beso.

La única flor que sigue naciendo en nuestra tierra pese a todo, regalada como herencia para todos, hasta los más pobres y olvidados. Maldito el que la deshaga y la marchite con su mano.

Por ella recordaremos que la vida era buena y valía la pena trabajar, sufrir o morir.

\section{NECESITAMOS LA DULZURA}

Necesitamos la dulzura para no quedar apresados en la inmensa red que tejen nuestras ambiciones y desconfianzas.

Sentimos como una vergüenza el que acaso sea verdad que el hombre parece ser un lobo para su próiimo. Pero por qué?

Quién pudo barrer de nuestros encuentros, de la piel que llevamos cubriendo nuestro cuerpo y nuestra alma, ese calor de la dulzura?

Nos hemos hecho demasiado fuertes y orgullosos. Nos hemos alejado hasta hacernos inaccesibles los unos para los otros. Por qué no volver en cada momento con el corazón tranquilo al que no busca?

Queremos que esa dulzura crezca por las calles donde hay ocasión de saludar, de respetarnos y ayudarnos mutuamente,

que esté flotando en el ambiente por donde discurre el ir y venir de nuestra jornada,

que haya algo de amable y de bueno en la mano que se alarga, en el rostro de los que nos observan, nos dirigen la palabra, nos enseñan o nos mandan.

En nuestro mundo dominado por la máquina y los números, por la rigidez de las leyes y los horarios por exigencias inapelables, la dulzura será como una ansiada zona verde en la que la vida respirará gozosa.

Qué paz más saludable puede haber para nuestro esfuerzo, qué re- 
compensa más sencilla se puede desear mientras somos compañeros en una marcha dura y prolongada?

La pondremos en nuestros ojos y en la palma de la mano, en el acento de la voz, para inundar con ella lo que rozamos cada día $y$ a los hombres que tratamos.

Ella será nuestra razón de amor que se hace gesto de comprensión de un hombre a otro. Y Dios estará cerca de nosotros.

\section{BUSCARE LA SOLEDAD}

Buscaré la soledad en un tiempo en que el ruido y la extroversión son como una necesidad universal que nos empobrece,

porque únicamente cuando sepa instalarme en ella equilibradamente estaré en condiciones de llevar mi aportación positiva al mundo.

No será un refugio para la debilidad sino la defensa necesaria de mi pensamiento y de mi acción.

pues desde ella podré ver más ampliamente la vida y escuchar sus voces sin confusión y comprobar la verdadera dimensión de mi ser.

Si me invade cuando menos lo esperaba, entonces la consideraré como una llamada que desde ti golpea con fuerza el posible vacío de mis días.

O quizás sea yo mismo quien la busque urgido por razón de los acontecimientos, como el ciervo que tiene sed busca los manantiales fríos.

En todo caso, defiende mi soledad para que pueda subsistir.

Dámela a su tiempo para que no me pierda como un desierto donde todo puede tener su espejismo, su propia sombra, su propio eco, menos yo,

porque quiero ser, desde allí, como la piedra que se hunde vertical en tu misterio y en el misterio de la vida, atravesando el tiempo y las cosas hasta el final.

\section{YO CREO EN TI}

Con mis hermanos los ignorantes y los sabios, los teólogo y los hom. bres de la calle, con el del rito sagrado y el de la herramien. $t a$, acepto tu misterio y creo en ti. 
$Y$ aunque me duele que otros no crean porque no quieren pensar en si acaso podrian descubrirte, o no pueden ya por demasiado inteligentes o demasiado hartos, yo creo en ti.

Sé que rápidamente y casi a voz en grito el mundo se hace inapetente de tu luz y que se ha cansado de seguir un camino señalado por tu palabra que no saben descifrar o no tienen tiempo de leer,

$y$ que hay entre los mejores de los que creian antes quienes se han olvidado de ti porque la vida les ha entretenido y ofuscado y ya no encuentran sentido a su plegaria y a su adoración.

Pero yo creo en ti. Y mi razón es vieja como el hombre y simple como tú en quien creo a pesar de todo, pese a mi dolor y mi combate continuo.

Está hecha de comprensión tranquila y no ambiciosa desde la vida que es bella y atormentada, desde el hombre que es bueno y a la vez zarandeado y derrotado por el mal.

No quiero enredarme en habladurias, sino que prefiero escuchar antes la palabra que sigues hablando sin cesar. $Y$ descubro que estás cerca de nosotros. $Y$ creo en ti.

De que tú seas un extraño, el mundo no tiene la culpa, ni los tiempos que vivimos, ni las técnicas que se descubren, ni el mal que siempre ha existido entre nosotros.

Somos nosotros. Y ya no queda por hacer sino que cada uno te piense con la simplicidad del aue espera de ti mismo luz para comprender $y$ poder decir: yo creo en ti.

\section{LAZOS DE SEDA}

Nos esclavizamos sin apenas sentirlo a la propaganda de lo superfluo, a la ley de lo más cómodo, a un viento triunfante que pasa por la superficie de la existencia barriendo cualquier gesto de sacrificio, sin oponer resistencia.

Es como una sed y un hambre artificial, creada por el tiempo, que nos obliga a desearlo todo y nos impide formular con valentía una renuncia.

Poco a poco se resiente nuestra voluntad con la cual se construye todo y se avanza, a través de los obstáculos por el destino de cada uno. 
Hay que alegrarse de la perfección técnica y de los hallazgos que hacen la vida más agradable, nos preservan del peligro o nos facilitan el trabajo y el caminar.

Pero no nos podemos resignar a que sea un imperativo que suplante al hombre, que arranca sus raíces de una tierra en la que ya no hay paraíso.

Nuestro tiempo se ríe o se compadece de lo heróico y ha proscrito cualquier forma de idealismo. Pero esto es como atar nuestras manos con un lazo de seda. Qué importa después lo que nos ofrezca?

Será necesario soltarse de un tirón, aunque la piel se destroce, para no perder esa básica libertad que se conquista con renuncias personales.

No podemos conformarnos con tópicos ni con sueños de burguesía mal disimulados. Si no que es preciso optar con sinceridad por la grandeza de que somos capaces.

Si el esfuerzo de la ascesis se nos perdona, nos encontraremos amontonados en una zona sin señales, perdidos, por falta de energía para buscar y andar los verdaderos caminos.

$\mathrm{Y}$ es el tirmpo cotidiano y las cosas, la elección y el compromiso, la fidelidad, el amor y la plegaria, lo que nos debe someter duramente como las manos del orfebre a su metal.

\section{DIA Y NOCHE}

Dia tras dia, todo el mundo que me encuentro hace su plegaria en torno mio y yo intento aprenderla para conocer la verdad de los hombres y la tuya.

En la ciudad modesta a donde se llega con bultos y sudor buscando un taxi y una morada donde reposar del cansancio.

La misma que amanece en seguida ruidosa y elegante, empobrecida con los humos, las construcciones y los derribos, el ajetreo de la muchedumbre que es como un bosque de ojos que hablan sin cesar por dentro de ellos mismos.

La muchedumbre de los hombres que desde la mañana se ponen a vivir cartera en mano a la universidad o a la oficina, de las muchachas arregladas de prisa aue cruzan las eceras como un regalo. Los de todos los días a quienes persigue el reloj en su memoria. 
$Y$ el hombre de la desgracia, el mismo ciego de siempre en la misma esquina, el vendedor de periódicos, el que recoge los cubos de basura en los portales.

$Y$ el hombre del autobús monótono, que como un cascarón lleva gente desconocida a todas partes, el de la tienda miserable, el del café abarrotado de clientes, el de las obras que despeja su rutina a golpe de hierros.

Es mi mundo que rueda por el día, gastado por veinticuatro horas, como un billete del metro. Que apenas descansa, que sabe lo que quiere y se olvida de ello, que parece que nunca llega adonde tiene pensado,

que trajina sin cesar por el día, con su rostro verdadero y su máscara. $Y$ en la noche enciende animado todas las farolas y letreros posibles para que se vea algo por fuera y se relaja en los bancos bajitos haciendo el amor.

$Y$ tú recogerás su plegaria multiforme y extraña? Creerás en sus palabras $y$ en sus gestos? De qué manera podrán conocer que tú les escuchabas y que su vida tenia un sentido?

\section{LAS PALABRAS}

Es una tormenta incontenible de palabras las que se nos echa encima y descarga su granizada sin piedad querámoslo o no.

Nos rodean palabras ofreciendo, señalando, gritando lo que nosotros querríamos pensar acaso por nuestra cuenta. Nos hacen un favor y nos destruyen por dentro.

Quisiéramos tener un espacio de claridad, despejado, para que nuestro corazón respirase a fondo, pero no lo encontramos, porque solo resta ya la fatiga y el olvido.

A qué hora podrá uno decir sus propias palabras, dejar hablar a su interior, salir del cerco salvaje de lo que hay que decir y oír y saber necesariamente, para poder expresar lo que de verdad había en él?

Necesitamos todavía que haya alguien que nos escuche, para que nuestras palabras no se las lleve el viento. Alguna vez encontramos un amigo dispuesto.

Pero te necesitamos a ti. Sólo tú eres la amplitud deseada donde podemos libertarnos de la mudez tiránica de este tiempo, donde 
se ensaya a soltar amarras y unas expresiones prefabricadas, para explicarnos tranquila y gozosamente.

En ti encuentro al que me escucha y va más allá de las palabras para acoger a mi persona. Cómo es posible que tu silencio resulte odioso a alguien?

Sólo tú eres el que así nos da lo que más necesitamos para vivir. Yo quiero hablarte ahora.

\section{LLEGAR A CASA}

Ya he llegado a casa, como otros cientos de veces, de andar por la calle, de vuelta de muchos sitios, de regreso de infinidad de salidas.

Vuelvo del trabajo, del encuentro con otros hombres que, como yo, abandonan su casa para hacer algo iuntos, hablar, conocer. nos, amarnos o combatirnos.

Aqui hay otro encuentro donde yo soy el mismo de siempre. Donde los otros que conviven me conocen y me hacen sitio. $Y$ yo llego con mi carga diaria, ellos lo saben.

Desearia traer felicidad $y$ dinamismo, abundancia $y$ buen talante. Pero no siempre resulta asi.

Yo no traigo nada a veces. $Y$ mi casa es también en ocasiones un encierro duro para mí. O no me dan nada cuando vuelvo necesitado de todo.

Qué otro lugar me queda, cuando el mundo es demasiado grande $y$ cada uno en él parece un habitante de una casa deshabitada?

Estoy seguro de que lo encontraria en ti, si supiese buscarte donde estás. Pero voy perdido e inquieto parque no sé cómo buscar. te o quizá ya no auiera hacerlo.

$Y$ sin embargo tienes tu morada en mí. Y eres la paz que no se delimita con paredes, ni se enumera en sitio determinado.

Si yo no reúno mi vida en ti, mi morada está desierta porque yo no estoy en mi sitio. Soy como el peso que tiene que apuntarse hacia su probia gravedad.

$Y$ me prequnto ahora: adónde iré. Señor? Si tú no estás en mí, en qué morada y entre quiénes descansaré yo? 


\section{CUANDO TODO ACABA}

Yo no quiero ser un hombre de mal gusto y oscurecido porque la vida es bella. Pero Tú me impones una memoria de todo lo que acaba.

Seguramente entendemos que hay un final para cada cosa. Que la vida es breve. Que una última pregunta queda pendiente de todo. Pero casi nadie se llega a preocupar.

Porque todo en torno nuestro se encarga del olvido. Es un acuerdo universal de desterrar el pensamiento de lo que acaba.

Los reclamos se hacen sobre lo nuevo, lo brillante, lo atrayente, lo que vive. $Y$ es la señal que traduce todo lo demás.

Quizá sea una suerte, pero yo que vivo también con todo eso descubro mi propio cansancio. $Y$ pienso que al final del camino habrá algo que nos interrogue.

Pero qué algo? Algo más entre tantas cosas como se vieron y se experimentaron? Ya no queda ni un resto de interés, ni de intención, porque está gastado.

Me encontraré una vez solo frente a algo verdaderamente grande: Tú mismo, Señor de nuestra vida que llegas para encontrarme a mí.

Tú que paras un movimiento creado por nosotros, sostenido por nosotros $y$ en el que nosotros nos afanamos por un tiempo.

Tú que impones el silencio último.

Tú que nos regresas a tu morada.

Tú que nos haces descansar.

Tú que recoges la cosecha de amor de nuestra vida.

He visto muchas cosas cada día y pienso en ellas recordándote a ti. Este es mi personal testimonio de haber comprendido a tiempo.

Los lugares, las personas, los trabajos, el amor y los libros, las ideas y las costumbres se han hecho carne de mi carne y me han llenado el corazón hasta el borde. Y quiero que esto sea mi ofrenda humilde para ese final.

\section{PROCESO A DIOS}

Mis hermanos los hombres de hoy se han hecho más audaces que nunca tratándose de ti. 
$Y$ ahora te procesan $y$ te hacen sentar en el banquillo que preparan sus libros y escenarios como a otro personaje cualquiera.

Siempre fuiste motivo de su inquietud, de su malestar intelectual, de su maldición y su tormento, pero quién tenía la culpa?

Ellos to quieren saber. Porque sus cosas no marchan o no encajan como quisieran en sus planes y no se sienten tranquilos.

Pero no sáben por dónde empezar porque las acusaciones son muy complejas y en un momento que no lo espera nadie, se vuelven contra ellos.

Se olvidan de que Tú no eres una potencia extranjera, ni un administrador general. Que no eres el refugio de todas las apelaciones faltas de sabiduria y de fe. Que no eres lo que ellos piensan.

Por eso quizá opten al final de todas sus especulaciones y representaciones teatrales, de todas las invectivas de palabra $y$ de es. crito por acusarte simplemente.

$Y$ como respuesta para más adelante se despoien de su fe y se olviden de ti, te hagan a un lado desacreditándote y se vuelvan a su faena creyéndose libres.

Tú mientras tanto permaneces en silencio poraue esto mismo lo venimos haciendo a lo largo de la Historia constantemente.

Si ellos te comprendieran bien, encontrarian la paz para su espiritu con la cual se interpretan mejor las cosas.

Pero cuando les dejarás caminar diciendo cosas extraviadas, ausentes de ti y envueltos en la oscuridad de la noche del mundo?

\section{NOSOTROS LOS CULPABLES}

La verdad es que ante un mundo que acusa, debemos levantarnos nosotros los testigos de una fe que ha debido pasar por todos los obstáculos.

Pero no para hablar tanto como para actuar. Porque las palabras han llegado a cansar a la gente.

Ya no es tiempo para polémicas o apologías, sino para el testimonio.

El mundo necesita ver y comprobar si nuestro Dios importa algo en esta hora:

quiere saber para qué sirve la fe en $\mathrm{El}$ de los piadosos y qué consecuencias valdría la pena de aceptar por ella. 
Y ya no hay otro camino que el del laborioso silencio desde nuestros puestos vitales para preparar eso que se impone.

Otra vez todo se reduce a demostrar si los creyentes llevan a su Dios en los labios o en el corazón,

y su sombra es la de un ídolo cualquira o penetra la realidad de nuestras existencias hasta el fondo.

Quién sino nosotros mismos somos el rostro de nuestro Dios?

Qué lástima darán nuestros rostros amargados, con cicatrices de decepción y aburrimiento!

Qué repulsión despertará nuestra plegaria impersonal y sin compromiso o nuestra adoración mecánica y legalizada!

¿Nos extrañará que parezcamos un pueblo a la deriva, sin fuerza espiritual para hacer cara a la tensión a que la vida nos somete?

Mejor es que nos levantemos y nos confesemos culpables para que este gesto revele una sinceridad salvadora.

$\mathrm{Y}$ los hombres reflexionen cada uno por su cuenta, mientras Dios, el acusado principal, alarga su silencio.

ANDRES G. NIÑO 